pace. The concept has changed from academic learning to experiential learning ${ }^{[2]}$ and soon we can hope that the concept of documentation will also be incorporated. An interlinked chain of events needs to be understood in this aspect. Previously, it was learning and doing only, then came learning by doing and now the mantra is learning by doing followed by documentation so that others can learn and integrate the existing knowledge with their clinical expertise to innovate newer techniques, which again need to be documented, to continue the education cycle. Another important issue is exposure/interest/ experience of our teachers. Owing to lack of teachers' initiative the young generation is not being trained in documentation. The documentation strategy should also be made an integral element of teachers' training.

To continue the education cycle, we need to have a fair idea of how to start, from where to start and what are the available resources. World-wide-web services are indispensable in this regard, and there are many databases such as COCHRANE database of systematic reviews $^{[3]}$ available free to the researchers belonging to the developing countries. In addition to this, renowned universities conduct online research methodology learning courses from time to time, which can be accessed through COURSERA ${ }^{[4]}$ etc. Knowing about the various categories/types of manuscripts is also important. We, as surgeons mostly talk of clinical documents, e.g., case series, reviews, case reports, new technique or innovations. However, there are many more ways of writing papers such as web search, embryology, anatomy, community care, public education, prevention and many more. We need to motivate our colleagues to think in this direction and prepare manuscripts on various such issues as well. Now, the time has come to get rid of anxiety about documentation and to take the initiative of documenting quality and not quantity research papers.

\title{
Taking the next step in documentation: Why and how?
}

Sir

Apropos the editorial entitled "Let's take the next step in the documentation," recently published in your esteemed journal. ${ }^{[1]}$

We commend Bhattacharya for very interesting and highly informative write up on the changing global trends in documentation strategy. The impetus on high-quality documentation has been greatly underemphasised in the existing medical education system. However fortunately, medical education system is transforming albeit at a slow
Himanshi Aggarwal, Pradeep Kumar

Department of Prosthodontics, Faculty of Dental Sciences, King George's Medical University, Lucknow, Uttar Pradesh, India

Address for correspondence: Dr. Pradeep Kumar, Room No. 404, E Block, Gautam Buddha Hostel, King George's Medical University, Lucknow, Uttar Pradesh, India. E-mail: drpradeepkmr@gmail.com

\section{REFERENCES}

1. Bhattacharya S. Let's take the next step in documentation. Indian J Plast Surg 2014;47:157-8. 
2. de Jong JA, Wierstra RF, Hermanussen J. An exploration of the relationship between academic and experiential learning approaches in vocational education. $\mathrm{Br} \mathrm{J}$ Educ Psychol 2006;76:155-69.

3. Available from: http://www.cochrane.org/. [Last accessed on 2014 Aug 20].

4. Available from: https://www.coursera.org/. [Last accessed on 2014 Aug 20].

\begin{tabular}{|l|l|}
\hline \multicolumn{2}{|c|}{ Access this article online } \\
\hline Quick Response Code: & Website: \\
\hline & www.jps.org \\
\cline { 2 - 2 } & DOI: \\
\hline
\end{tabular}

